\title{
Emerging paradigms of regulated microRNA processing
}

\author{
Martin A. Newman and Scott M. Hammond ${ }^{1}$ \\ Department of Cell and Developmental Biology, Lineberger Comprehensive Cancer Center, University of North Carolina, \\ Chapel Hill, North Carolina 27599, USA
}

\begin{abstract}
MicroRNAs (miRNAs) modulate a broad range of gene expression patterns during development and tissue homeostasis, and in the pathogenesis of disease. The exquisite spatio-temporal control of miRNA abundance is made possible, in part, by regulation of the miRNA biogenesis pathway. In this review, we discuss two emerging paradigms for post-transcriptional control of miRNA expression. One paradigm centers on the Microprocessor, the protein complex essential for maturation of canonical miRNAs. The second paradigm is specific to miRNA families, and requires interaction between RNA-binding proteins and cis-regulatory sequences within miRNA precursor loops.
\end{abstract}

The microRNA (miRNA) biogenesis pathway is a series of biochemical steps that converts the primary miRNA transcript (pri-miRNA) to the biologically active, mature miRNA (Kim et al. 2009). The characterized first step is the recognition of the canonical stem-loop structure of the miRNA by the Microprocessor complex. This leads to ribonucleolytic cleavage of the pri-miRNA, removal of the flanking sequences, and liberation of the stem-loop precursor miRNA (pre-miRNA). The pre-miRNA is exported to the cytoplasm via the Exportin5 pathway. The precursor is then cleaved by the ribonuclease enzyme Dicer. This leads to an 22 -nucleotide duplex, one strand of which is loaded into the Argonaute-containing RNAinduced silencing complex (RISC). This represents the endpoint of biogenesis; the single-stranded mature miRNA is ready to guide mRNA binding, which leads to translational repression and/or mRNA destabilization (Kim et al. 2009). As an exception to this rule, the less abundant "mirtrons" circumnavigate Drosha processing and are processed only by Dicer (Okamura et al. 2008).

In principle, miRNA abundance could be controlled at transcription of the pri-miRNA, during any of the biogenesis steps, or at turnover of the mature miRNA. Control at transcription is well established. Most miRNAs are transcribed by RNA polymerase II, and their upstream

[Keywords: Drosha; KSRP; Lin28; miRNA; microRNA; microprocessor] ${ }^{1}$ Corresponding author.

E-MAIL hammond@med.unc.edu; FAX (919) 966-1856.

Article is online at http://www.genesdev.org/cgi/doi/10.1101/gad.1919710. regulatory regions contain canonical core promoters and enhancers (Lee and Dutta 2009). Early studies by several laboratories, however, found that mature miRNA expression does not always correlate with expression of the primiRNA (Obernosterer et al. 2006; Thomson et al. 2006; Blenkiron et al. 2007; Wulczyn et al. 2007). Thus, miRNAs themselves must be post-transcriptionally regulated. In fact, regulation at multiple biogenesis steps and at turnover of the mature miRNA has now been established (Hwang et al. 2007; for review, see Pawlicki and Steitz 2009). This review focuses on the regulation of miRNA production during biogenesis. The majority of discoveries on miRNA regulation can be distilled down to two contrasting paradigms based on the biochemical point of regulation: at the Microprocessor complex, and at the terminal loop of specific miRNA precursors.

\section{Multiple regulatory events converge on the Microprocessor complex}

As the first processing step in miRNA biogenesis, the Microprocessor is positioned to play a pivotal role in the regulation of mature miRNA abundance. This complex is minimally composed of two proteins: the dsRNA-binding protein DGCR8 (Pasha), and the RNase III enzyme Drosha (Lee et al. 2003; Denli et al. 2004; Gregory et al. 2004; Han et al. 2004; Landthaler et al. 2004). These two proteins represent the essential requirements for the first processing step, defined by reconstitution of activity with purified recombinant proteins. In human cell extracts, however, Drosha has been described to reside in multiple complexes (Gregory et al. 2004). A complex that is comprised solely of Drosha and DGCR8 has robust primiRNA processing activity. A second, larger complex has multiple accessory proteins, yet also has pri-miRNA processing activity. It is not clear whether this large complex is assembled around RNAs, since many of the accessory factors contain RNA interaction motifs, and RNase treatment of extracts has been shown to shift the size of the Drosha complex (Han et al. 2004). The accessory proteins in this large Drosha complex include the EWSR1, Fus, numerous heterogenous nuclear RNA complex (hnRNP) proteins, and the DEAD-box helicases p68(DDX5) and p72(DDX17). While the exact biochemical composition of the cellular Microprocessor is unknown, 
a recent collection of studies implicates p68 and p72 as important cofactors of the Microprocessor in vivo.

\section{Integrating signal transduction with Drosha processing: the role of $p 68$ and $p 72$}

The p68 and p72 helicases are conserved across eukaryotes and are implicated in diverse RNA processing pathways (for review, see Fuller-Pace 2006). In cell-free assays, both proteins have moderately processive ATPdependent RNA unwinding and annealing activities. In cells, the proteins have been linked to several pathwaysmost notably splicing and transcription. p68 was isolated as a component of the spliceosome, and specifically is required for proper assembly-disassembly of the U1 5' splice site. Interestingly, p68 and p72 interact with several components of the transcriptional machinery, including RNA polymerase II and CBP/p300. This raises the interesting possibility that one role of $\mathrm{p} 68$ is to coordinate/colocalize the splicing machinery with the transcription apparatus. Independent of this, p68 acts as a transcriptional cofactor for several factors, including CBP/p300, p53, and the estrogen receptor $\alpha(\mathrm{ER} \alpha)$. For example, etoposide-mediated induction of p53-responsive genes is dependent on p68. Remarkably, this requirement is not dependent on p68 helicase activity, as an ATPase mutant allele of p68 rescued induction by p53. RNA binding, however, was still required. Similarly, ER $\alpha$ coactivation is not dependent on helicase activity. This suggests a model whereby p68 and possibly p72 mediate assembly of transcription complexes at promoters and recruit the splicing machinery to the promoter, thus facilitating cotranscriptional splicing events.

Recently, p68 and p72 were implicated as regulators of processing for many miRNAs (Fukuda et al. 2007). This was first demonstrated in studies on mice that are homozygous null for either p68 or p72. For both genes, loss of function is lethal; p68-null mice die at embryonic day 11.5, and p72-null mice are postnatal lethal. miRNA expression analysis of null embryos indicated reduced mature miRNA levels. Whether the reduction of these miRNAs was due to loss of function in the respective helicase, or whether the mutant phenotype led to aberrant miRNA expression due to developmental alterations, remains to be addressed. However, mouse embryonic fibroblasts (MEFs) derived from p72-null embryos had a reduction in at least two miRNAs (miR-16 and mir145), but not all miRNAs, and this reduction could be rescued by introduction of ectopic p72. pri-miRNA expression was unaffected, demonstrating an alteration in processing of the miRNA precursors. Interestingly, ATPase mutant alleles of $\mathrm{p} 72$ did not rescue production of either miR-16 or miR-145. This is in contrast to the transcriptional coactivation role for $\mathrm{p} 68$, which was not dependent on helicase activity. Therefore, for at least these two miRNAs, a role for helicase activity (or possibly ATP-dependent conformation change) is required. Furthermore, cell-free extracts that lack either p68 or p72 are inefficient at conversion of pri-miR-16 to the corresponding precursor miRNA. RNA immunoprecipitation (RIP) experiments in the same study showed that Drosha recruitment to pri-miR-199a and pri-miR-214 was lost upon RNAi-mediated depletion of p68 or in p72 knockout cells, consistent with the observation that mature miR199a and miR-214 levels are lower in p68/p72-null embryos. Thus, in vivo, these helicases seem to be required to properly recruit the Microprocessor to some pri-miRNAs. As discussed below, it is now clear that multiple critical cellular signaling pathways use the p68 and p72 association with Microprocessor to effect regulation of primiRNA processing.

\section{Transforming growth factor $\beta$ /bone morphogenic protein (TGF- $\beta / B M P)$}

The first study to report a signal transduction-mediated change in miRNA biogenesis demonstrated that the TGF- $\beta$ and BMP pathways specifically promote processing of pri-miR-21 (Davis et al. 2008). The contractile phenotype of human smooth muscle cells treated with TGF- $\beta$ or BMP was found to be dependent on the rapid upregulation of miR-21. Interestingly, this rapid increase in miR-21 occurred post-transcriptionally; quantitative realtime PCR (qRT-PCR) experiments revealed that pre-miR21 and mature miR-21 levels quickly increased upon TGF- $\beta$ and BMP treatment, while levels of pri-miR-21 were unchanged. Davis et al. (2008) then reasoned that SMAD proteins might be the intermediaries responsible for connecting these signaling pathways with miR-21 processing, as they are translocated into the nucleus upon TGF- $\beta$ or BMP signaling and are known to bind DNA. Furthermore, a previous study reported that SMAD1 interacts directly with the RNA helicase p68 (Warner et al. 2004). Accordingly, depletion of receptor-specific SMADs (SMAD1 and SMAD5) or p68 abrogated the BMP and TGF- $\beta$-driven increase in pri-miR-21 processing. Some initial mechanistic insight was also provided; GST pulldowns with recombinant SMADs in nuclear extracts indicated that $\mathrm{p} 68$ binds to the MH2 domain of R-SMADs while the MH1 domain binds to pri-miR-21 either directly or through other unknown factors.

The full complement of miRNAs that are regulated by this pathway is presently unknown. Since the TGF- $\beta$ and BMP signaling pathways regulate many biological phenomena, it is possible that these pathways stimulate processing of other pri-miRNAs; indeed, Davis et al. (2008) also observed that pri-miR-199a processing is regulated in this manner. This is not surprising, since these signaling pathways converge on miRNA processing via p68, and this helicase has been shown to modulate a number of miRNAs.

\section{The p53 DNA damage pathway}

Unexpectedly, a subsequent study demonstrated that the tumor suppressor p53 also promotes pri-miRNA processing. It was noted that many miRNAs depleted in p72 knockout mice are coincidentally also up-regulated by the DNA-damaging agent Doxorubicin (Dox). As Dox strongly stimulates p53 activity, leading to induction of p53-responsive genes, it was perhaps not surprising that 
p53 might also induce the expression of miRNAs. In fact, miR-34 had been well established as a direct p53 transcriptional target (He et al. 2007). However, after measuring pri-miRNA expression levels of induced miRNAs, Suzuki et al. (2008) realized that these miRNAs were not being induced transcriptionally. Rather, processing at the Drosha step was triggered. In hindsight, this was not so surprising: p68 was known to regulate pri-miRNA processing, and the helicase had been shown to interact with p53 as a coactivator; ergo, p53 might be able to directly modulate miRNA processing (Bates et al. 2005). Accordingly, coimmunoprecipitation experiments as well as in vitro Drosha processing assays demonstrated that p53 associated with the large Drosha complex upon treatment of cells with Dox. Intriguingly, p53 alleles with known oncogenic activity decreased processing efficiency of p53-targeted miRNAs by disrupting p68's association with Drosha, thus displacing the Drosha complex from selected pri-miRNAs. Again, the biochemical basis of p53's association with p68 and the subsequent increase in target pri-miRNA processing remains obscure. Detailed structure-function studies will be needed to understand how p68 binding to p53 (both wild-type and oncogenic alleles) modulates Drosha's ability to process pri-miRNAs.

\section{ER $\alpha /$ estrogen}

Another interesting report revealed how a signaling cascade can negatively regulate pri-miRNA processing. Kato and colleagues (Endoh et al. 1999) noticed that ER $\alpha$ was shown previously to interact with p68 and p72. Augmentation of the $\mathrm{ER} \alpha$ signaling pathway produced a striking pattern of changes in certain miRNAs; many miRNAs were increased in $\mathrm{ER} \alpha^{-1-}$ mice (Yamagata et al. 2009). Furthermore, administration of estradiol (E2) to ovariectomized mice reduced the same miRNAs within the uterus. Importantly, this effect of E2/ER $\alpha$ could be recapitulated in the human breast cancer cell line MCF7. The physiological importance of ER $\alpha$-regulated miRNA biogenesis was evident from the observation that the $3^{\prime}$ untranslated region (UTR) of VEGF, an ER $\alpha$ target gene, is targeted by ER $\alpha$-repressed miRNAs. Yamagata et al. (2009) then demonstrated in vitro that E2-bound ER $\alpha$ could directly inhibit Drosha processing of ER $\alpha$ target pri-miRNAs. This study delved into more biochemical detail than the reports mentioned above: It was determined that p68 and/or p72 bridge the interaction between Drosha and E2-bound ER $\alpha$; this interaction requires the C-terminal domain of Drosha and the $\mathrm{N}$ terminus of $\mathrm{ER} \alpha$. Thus, when $\mathrm{ER} \alpha$ is recruited to the large Drosha complex in an E2-dependent manner, Drosha is dissociated from ER $\alpha$-targeted pri-miRNA loci. It will be interesting to determine whether ER $\alpha / \mathrm{E} 2$ weakens the overall integrity of the large Drosha complex, or simply its affinity for certain pri-miRNAs.

\section{A pri-miRNA processing holoenzyme? Facts} and future directions

As mentioned above, Drosha isolated from mammalian extracts exists in a large complex with many different
RNA-binding proteins. The role of most of these Droshaassociated factors in pri-miRNA processing is not clear. It seems entirely possible that many of the factors purified in the large cellular Drosha complex may be the result of a nonphysiological RNA-protein complex assembled upon cell lysis. In support of this, while the dsRNAbinding proteins NFAT-90 and NFAT-45 were shown previously to be Drosha-associated factors (Gregory et al. 2004), one recent study showed that this heterodimer does not interact with Drosha and, in fact, inhibits processing of certain pri-miRNAs (Gregory et al. 2004; Sakamoto et al. 2009). This study underscores the need to more carefully analyze the functional interactions between Drosha-DGCR8 and the many auxiliary factors that are contained within the large complex. As with p68 and p72, there may indeed be important roles for other Drosha-associated factors, as general Microprocessor cofactors or as factors that integrate specific cell signaling pathways with pri-miRNA processing.

So, does Drosha/DGCR8 function within the context of a larger holoenzyme in vivo? The studies mentioned above suggest that, of the Drosha-associated factors initially identified, p68 and p72 are the first to be assigned as important cofactors in Drosha processing of certain primiRNAs. Taken together, the aforementioned studies suggest a model shown in Figure 1. Drosha processing is known to occur cotranscriptionally (Kim et al. 2009). p68 has been proposed to link mRNA transcription to splicing (Fuller-Pace and Ali 2008). Therefore, p68 and/or p72 might perform a similar function with miRNAs. That is, p68 might act as a bridge between the Microprocessor and specific miRNAs, at the RNA polymerase holoenzyme during transcription. This effect might be independent of helicase activity, as is the role of p68 in mRNA transcriptional events. However, p72 activation of miR-16 and miR145 processing is ATP-dependent, suggesting a second, helicase-dependent role for p72 (Fukuda et al. 2007). This is further supported by the fact that p72 modulates Microprocessor function in cell-free extracts that is unlinked to transcription. It is important to note that all of these cell-free assays are based on crude extracts or on partially purified components. Without an exact understanding of the protein composition of the assays, it is difficult to fully understand the role of these accessory proteins.

\section{It's all in the loop: specific interactions between regulatory proteins and the terminal loop of miRNA precursors}

As discussed above, one mode of regulated miRNA biogenesis occurs through modulation of Microprocessor activity. A second regulatory phenomenon occurs when RNA-binding proteins bind directly to specific sequences within pri-miRNAs, diverting the RNA away from biogenesis events, and often leading to degradation of the RNA.

\section{Lin28 as a master regulator of let-7 production}

let-7 is one of the most abundant miRNA families in mammals, with high expression in essentially all adult 

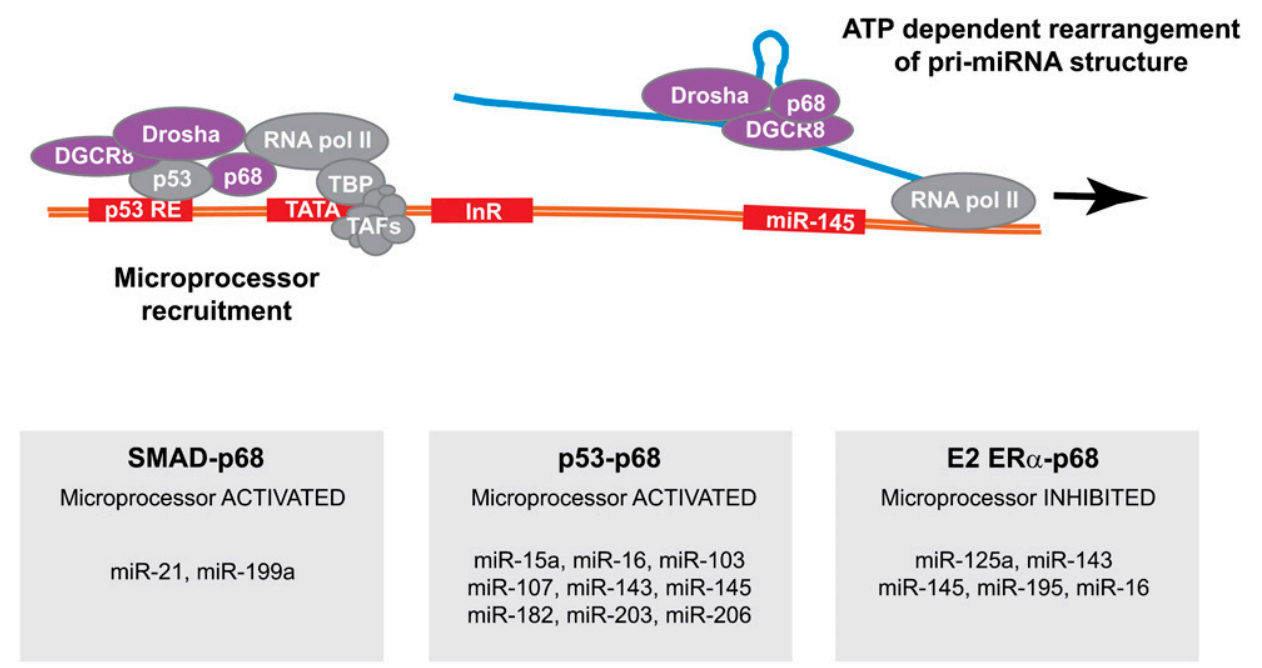

Figure 1. Model for regulation of miRNA biogenesis at the Microprocessor. Multiple signaling pathways converge on the Microprocessor via the helicases p68 and p72. These helicases have ATP-dependent and ATP-independent functions. We present a model whereby both functions affect miRNA production. The ATP-independent functions have been linked with recruitment of processing activities to RNA polymerase. This could be used by the miRNA pathway as a manner of recruitment of the Microprocessor to transcription sites. The ATP-dependent role of p68 has been described as maintenance of proper RNA secondary structure to facilitate Drosha cleavage. The components of the RNA polymerase preinitiation complex and Microprocessor are simplified. (TBP) TATAbinding protein; (TAF) TBP-associated factors; (InR) initiator element; (RE) response element.

tissues. In embryonic cells, in contrast, mature let-7 is present at $\sim 1000$-fold lower levels. Unexpectedly, pri-let-7 expression is constant throughout development, thus providing a dramatic illustration of post-transcriptional regulation of a miRNA (Thomson et al. 2006). Research published over the past 2 years has demonstrated that the RNA-binding protein Lin28 blocks let-7 miRNA maturation in early embryonic cells, and the related Lin28B contributes to let-7 reduction in cancer (for review, see Viswanathan and Daley 2010). Initial studies demonstrated that Lin28 represses Drosha and Dicer processing of let-7 in vitro by binding to conserved sequences in the precursor loop. Furthermore, overexpression of Lin28 in differentiated cells and knockdown of Lin28 in embryonic cells resulted in the depletion and accumulation of mature let-7, respectively. The exact mechanism whereby Lin28 blocks processing steps is unknown. What was clear is that the blocked pri-miRNA/ pre-miRNA was not accumulating in cells, suggesting a turnover mechanism. We now know, in the case of the pre-let-7, that Lin28 directly recruits a poly(U) polymerase, terminal (U) transferase (TUT4), to the precursor RNA (Hagan et al. 2009; Heo et al. 2009; Lehrbach et al. 2009). Oligo-uridylation of the precursor occurs, which triggers degradation. The fate of the blocked pri-let-7 is still unknown (see Fig. 2).

The story of Lin 28 thus comes full circle. This embryonic stem (ES) cell-specific RNA-binding protein was one of the earliest-recognized let-7 targets (Reinhart et al. 2000). In embryonic development, its expression is reciprocal to that of mature let-7. Concordantly, Lin 28 overexpression, in combination with several ES-specific transcription factors, is sufficient to reprogram somatic cells into induced pluripotent stem (iPS) cells (Yu et al. 2007).

\section{KH-type splicing regulatory factor (KSRP) binds let-7} loop sequences and activates miRNA processing

Recently, a role was uncovered for the RNA-binding protein KSRP in promoting miRNA biogenesis in mammals (Trabucchi et al. 2009). This protein binds specifically to 5'guanosine-rich patches on the loop region of several miRNA precursors, including let-7. Knockdown of KSRP significantly decreases the expression of these miRNAs, in part by preventing efficient recruitment of Drosha and Dicer to the pri-miRNA and pre-miRNA, respectively. The obvious question is: How can $\operatorname{Lin} 28$ and KSRP bind to the let-7 loop, but with opposing terminal outcomes? Interestingly, while recombinant fragments of KSRP bind to the let-7 terminal loop with high affinity in vitro, KSRP cannot bind to pri-let-7 in embryonic cells, which have abundant Lin28. This suggests a model whereby Lin 28 and KSRP bind in a mutually exclusive manner. Specifically, Lin 28 may sterically hinder KSRP binding even though the two proteins bind to unique sequences on opposites sides of the let-7 loop. Alternatively, an unidentified factor in embryonic cells could bind cooperatively with Lin 28 to let-7 loops, thereby preventing KSRP binding.

\section{Regulation of miRNA processing by hnRNP proteins}

While the above examples point to regulators with specific functions, there are other examples of RNA-binding proteins with a pleiotropic function in RNA biogenesis. One such example is the highly abundant RNA-binding protein hnRNP A1. This protein has been well established as a component of many hnRNPs and performs essential functions in many RNA processing and transport pathways (He and Smith 2009). Using cross-linking 


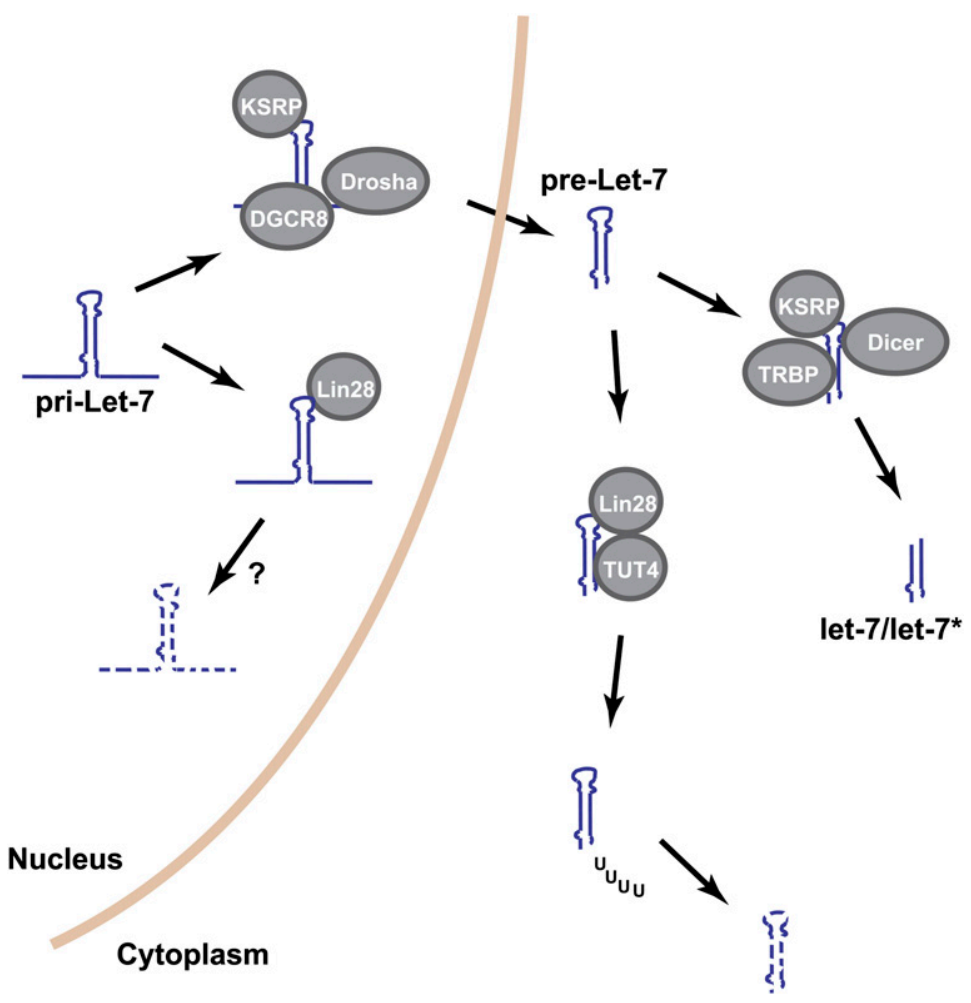

Figure 2. Model for regulation of miRNA biogenesis by loop-binding proteins. The processing of let-7 is shown, with contrasting effects of an inhibitor (Lin28) and an activator (KSRP). Both regulators have been linked to the Drosha and Dicer step. In addition, Lin28 promotes degradation of the precursor. Degradation of pri-let-7 has not been demonstrated; however, pri-let-7 does not accumulate in the presence of Lin28 blockade, and therefore may be actively degraded. (TUT4) terminal (U) transferase; (KSRP) KH-type splicing regulatory factor. immunoprecipitation (CLIP) (Ule et al. 2005), Guil and Caceres (2007) demonstrated that hnRNP Al interacts with specific nucleotides of the loop and stem of primiR-18a. This miRNA is one of six miRNA stem-loops on the oncogenic polycistron miR-17-92. The role for hnRNP Al in miRNA processing was demonstrated when HeLa extracts depleted of hnRNP A1 by RNAi failed to process pri-miR-18a from pri-miR-17-92, while the other pri-miRNAs in the polycistron were still processed. Interestingly, when recombinant hnRNP A1 was added back to the depleted extract, pri-miR-18a processing was not restored; this suggests that hnRNP A1 might have to be "precomplexed" with other RNAbinding factors in order to act specifically on pri-miR$18 \mathrm{a}$. Of course, it is also possible that bacterially purified hnRNP Al is missing post-translational modifications that are required for the positive regulation of pri-miR18 a processing.

Further studies demonstrated that hnRNP A1 binding to the loop and stem regions of pri-miR-18a relaxes the stem region and facilitates cleavage by Drosha. Bioinformatic analysis and RNA affinity purification using miRNA loop sequences, as well as in vitro Drosha assays, revealed that many hnRNP proteins could potentially form an extensive interaction network with miRNA loops (Michlewski et al. 2008). Thus, hnRNPs may broadly control the levels of miRNAs at the posttranscriptional level. The general physiological functions of hnRNP-miRNA loop interactions remain to be elucidated; ultimately, it will be important to understand the global distribution of hnRNP proteins between miRNAs and non-miRNA-containing substrates.

\section{Contrasting mechanisms allow fine-tuned expression of miRNAs}

We discussed two paradigms for regulated miRNA biogenesis. Control at the Microprocessor allows integration of signaling events from many pathways, leading to changes in expression of divergent miRNA families. All of the discussed events are mediated by the helicases p68 and $\mathrm{p} 72$. In many cases, the regulated miRNA families are similar, but there are notable exceptions. So how does this pathway allow specificity? Some interaction with the pri-miRNA must confer specificity. In the case of SMAD regulation of miR-21 processing, specificity could arise from interaction of the pri-miRNA with the SMADinteracting protein SNIP1. This coactivator protein had independently been shown to affect miRNA processing, and its Arabidopsis homolog has direct RNA-binding activity (Yu et al. 2008). In other cases, the key regulatory protein might itself interact with the pri-miRNA. As an example, p53 can immunoprecipitate pri-miR-16; but is there a direct interaction between p53 and the primiRNA, or is it bridged by p68? Interestingly, many transcription factors, including p53, have been shown to have RNA-binding activity (Riley and Maher 2007). Such interactions may provide the critical specificity. Of course, unidentified proteins may be part of the Microprocessor, possibly as a transient complex assembled after signal reception. Clearly, to fully understand this complex, we need better characterization of components, and ultimately reconstitution in defined activity assays. In contrast with the Microprocessor paradigm, the loop-binding regulators clearly have a mechanism for specificity. In the 
case of Lin28, the expression of that regulator is confined to the stem cell compartment, providing an obvious mechanism of control. KSRP and the various hnRNP proteins, in contrast, are widely expressed. Their biological function in the miRNA pathway is still poorly understood.

In addition to these paradigms, other regulatory events during miRNA biogenesis have been described, but could not be included in this review. For example, the metabolite heme can modulate Microprocessor function, although the biological role of this effect is unclear (Faller et al. 2007). The nuclear cap-binding complex component ARS2 is important for fidelity of Microprocessor cleavage (Gruber et al. 2009). The miRNA primary sequence can be altered by A-I editing, leading to altered processing and function (Yang et al. 2006). When taken into consideration, it is clear that miRNA processing is regulated in a complex manner, and we are only beginning to understand its true nature.

\section{Acknowledgments}

We thank the Hammond laboratory for discussions on the manuscript. Funding in the Hammond laboratory is provided by the National Institutes of Health.

\section{References}

Bates GJ, Nicol SM, Wilson BJ, Jacobs AM, Bourdon JC, Wardrop J, Gregory DJ, Lane DP, Perkins ND, Fuller-Pace FV. 2005. The DEAD box protein p68: A novel transcriptional coactivator of the p53 tumour suppressor. EMBO J 24: 543553.

Blenkiron C, Goldstein LD, Thorne NP, Spiteri I, Chin SF, Dunning MJ, Barbosa-Morais NL, Teschendorff AE, Green AR, Ellis IO, et al2007. MicroRNA expression profiling of human breast cancer identifies new markers of tumor subtype. Genome Biol 8: R214. doi: 10.1186/gb-2007-8-10-r214.

Davis BN, Hilyard AC, Lagna G, Hata A. 2008. SMAD proteins control DROSHA-mediated microRNA maturation. Nature 454: 56-61.

Denli AM, Tops BB, Plasterk RH, Ketting RF, Hannon GJ. 2004. Processing of primary microRNAs by the Microprocessor complex. Nature 432: 231-235.

Endoh H, Maruyama K, Masuhiro Y, Kobayashi Y, Goto M, Tai H, Yanagisawa J, Metzger D, Hashimoto S, Kato S. 1999. Purification and identification of p68 RNA helicase acting as a transcriptional coactivator specific for the activation function 1 of human estrogen receptor $\alpha$. Mol Cell Biol 19: 53635372.

Faller M, Matsunaga M, Yin S, Loo JA, Guo F. 2007. Heme is involved in microRNA processing. Nat Struct Mol Biol 14: 23-29.

Fukuda T, Yamagata K, Fujiyama S, Matsumoto T, Koshida I, Yoshimura K, Mihara M, Naitou M, Endoh H, Nakamura T, et al. 2007. DEAD-box RNA helicase subunits of the Drosha complex are required for processing of rRNA and a subset of microRNAs. Nat Cell Biol 9: 604-611.

Fuller-Pace FV. 2006. DExD/H box RNA helicases: Multifunctional proteins with important roles in transcriptional regulation. Nucleic Acids Res 34: 4206-4215.

Fuller-Pace FV, Ali S. 2008. The DEAD box RNA helicases p68 (Ddx5) and p72 (Ddx17): Novel transcriptional co-regulators. Biochem Soc Trans 36: 609-612.
Gregory RI, Yan KP, Amuthan G, Chendrimada T, Doratotaj B, Cooch N, Shiekhattar R. 2004. The Microprocessor complex mediates the genesis of microRNAs. Nature 432: 235-240.

Gruber JJ, Zatechka DS, Sabin LR, Yong J, Lum JJ, Kong M, Zong WX, Zhang Z, Lau CK, Rawlings J, et al. 2009. Ars2 links the nuclear cap-binding complex to RNA interference and cell proliferation. Cell 138: 328-339.

Guil S, Caceres JF. 2007. The multifunctional RNA-binding protein hnRNP A1 is required for processing of miR-18a. Nat Struct Mol Biol 14: 591-596.

Hagan JP, Piskounova E, Gregory RI. 2009. Lin28 recruits the TUTase Zcchc11 to inhibit let-7 maturation in mouse embryonic stem cells. Nat Struct Mol Biol 16: 1021-1025.

Han J, Lee Y, Yeom KH, Kim YK, Jin H, Kim VN. 2004. The Drosha-DGCR8 complex in primary microRNA processing. Genes Dev 18: 3016-3027.

He Y, Smith R. 2009. Nuclear functions of heterogeneous nuclear ribonucleoproteins A/B. Cell Mol Life Sci 66: 1239-1256.

He X, He L, Hannon GJ. 2007. The guardian's little helper: MicroRNAs in the p53 tumor suppressor network. Cancer Res 67: 11099-11101.

Heo I, Joo C, Kim YK, Ha M, Yoon MJ, Cho J, Yeom KH, Han J, Kim VN. 2009. TUT4 in concert with Lin28 suppresses microRNA biogenesis through pre-microRNA uridylation. Cell 138: 696-708.

Hwang HW, Wentzel EA, Mendell JT. 2007. A hexanucleotide element directs microRNA nuclear import. Science 315: $97-$ 100.

Kim VN, Han J, Siomi MC. 2009. Biogenesis of small RNAs in animals. Nat Rev Mol Cell Biol 10: 126-139.

Landthaler M, Yalcin A, Tuschl T. 2004. The human DiGeorge syndrome critical region gene 8 and its $D$. melanogaster homolog are required for miRNA biogenesis. Curr Biol 14: 2162-2167.

Lee YS, Dutta A. 2009. MicroRNAs in cancer. Annu Rev Pathol 4: 199-227.

Lee Y, Ahn C, Han J, Choi H, Kim J, Yim J, Lee J, Provost P, Radmark O, Kim S, et al. 2003. The nuclear RNase III Drosha initiates microRNA processing. Nature 425: 415-419.

Lehrbach NJ, Armisen J, Lightfoot HL, Murfitt KJ, Bugaut A, Balasubramanian S, Miska EA. 2009. LIN-28 and the poly(U) polymerase PUP-2 regulate let-7 microRNA processing in Caenorhabditis elegans. Nat Struct Mol Biol 16: 1016-1020.

Michlewski G, Guil S, Semple CA, Caceres JF. 2008. Posttranscriptional regulation of miRNAs harboring conserved terminal loops. Mol Cell 32: 383-393.

Obernosterer G, Leuschner PJ, Alenius M, Martinez J. 2006. Post-transcriptional regulation of microRNA expression. RNA 12: 1161-1167.

Okamura K, Chung WJ, Lai EC. 2008. The long and short of inverted repeat genes in animals: MicroRNAs, mirtrons and hairpin RNAs. Cell Cycle 7: 2840-2845.

Pawlicki JM, Steitz JA. 2009. Nuclear networking fashions premessenger RNA and primary microRNA transcripts for function. Trends Cell Biol 20: 52-61.

Reinhart BJ, Slack FJ, Basson M, Pasquinelli AE, Bettinger JC, Rougvie AE, Horvitz HR, Ruvkun G. 2000. The 21-nucleotide let-7 RNA regulates developmental timing in Caenorhabditis elegans. Nature 403: 901-906.

Riley KJ, Maher LJ III. 2007. p53 RNA interactions: New clues in an old mystery. RNA 13: 1825-1833.

Sakamoto S, Aoki K, Higuchi T, Todaka H, Morisawa K, Tamaki N, Hatano E, Fukushima A, Taniguchi T, Agata Y. 2009. The NF90-NF45 complex functions as a negative regulator in the microRNA processing pathway. Mol Cell Biol 29: 37543769. 
Suzuki HI, Yamagata K, Sugimoto K, Iwamoto T, Kato S, Miyazono K. 2009. Modulation of microRNA processing by p53. Nature 460: 529-533.

Thomson JM, Newman M, Parker JS, Morin-Kensicki EM, Wright T, Hammond SM. 2006. Extensive post-transcriptional regulation of microRNAs and its implications for cancer. Genes Dev 20: 2202-2207.

Trabucchi M, Briata P, Garcia-Mayoral M, Haase AD, Filipowicz W, Ramos A, Gherzi R, Rosenfeld MG. 2009. The RNAbinding protein KSRP promotes the biogenesis of a subset of microRNAs. Nature 459: 1010-1014.

Ule J, Jensen K, Mele A, Darnell RB. 2005. CLIP: A method for identifying protein-RNA interaction sites in living cells. Methods 37: 376-386.

Viswanathan SR, Daley GQ. 2010. Lin28: A microRNA regulator with a macro role. Cell 140: 445-449.

Warner DR, Bhattacherjee V, Yin X, Singh S, Mukhopadhyay P, Pisano MM, Greene RM. 2004. Functional interaction between Smad, CREB binding protein, and p68 RNA helicase. Biochem Biophys Res Commun 324: 70-76.

Wulczyn FG, Smirnova L, Rybak A, Brandt C, Kwidzinski E, Ninnemann O, Strehle M, Seiler A, Schumacher S, Nitsch R. 2007. Post-transcriptional regulation of the let-7 microRNA during neural cell specification. FASEB J 21: 415-426.

Yamagata K, Fujiyama S, Ito S, Ueda T, Murata T, Naitou M, Takeyama K, Minami Y, O'Malley BW, Kato S. 2009. Maturation of microRNA is hormonally regulated by a nuclear receptor. Mol Cell 36: 340-347.

Yang W, Chendrimada TP, Wang Q, Higuchi M, Seeburg PH, Shiekhattar R, Nishikura K. 2006. Modulation of microRNA processing and expression through RNA editing by ADAR deaminases. Nat Struct Mol Biol 13: 13-21.

Yu J, Vodyanik MA, Smuga-Otto K, Antosiewicz-Bourget J, Frane JL, Tian S, Nie J, Jonsdottir GA, Ruotti V, Stewart R, et al. 2007. Induced pluripotent stem cell lines derived from human somatic cells. Science 318: 1917-1920.

Yu B, Bi L, Zheng B, Ji L, Chevalier D, Agarwal M, Ramachandran V, Li W, Lagrange T, Walker JC, et al. 2008. The FHA domain proteins DAWDLE in Arabidopsis and SNIP1 in humans act in small RNA biogenesis. Proc Natl Acad Sci 105: 1007310078 . 


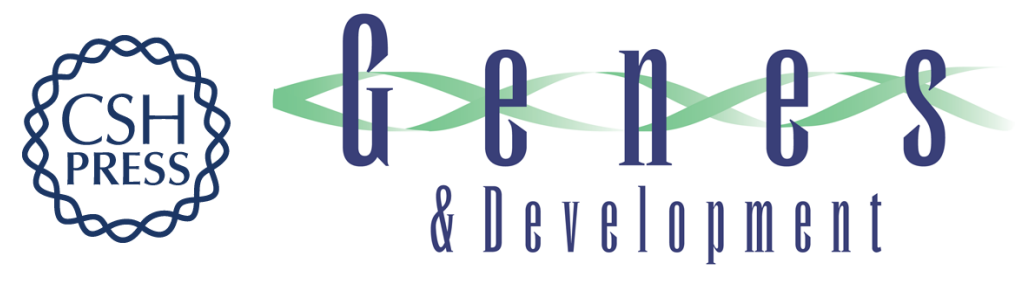

\section{Emerging paradigms of regulated microRNA processing}

Martin A. Newman and Scott M. Hammond

Genes Dev. 2010, 24:

Access the most recent version at doi:10.1101/gad.1919710

References This article cites 41 articles, 10 of which can be accessed free at: http://genesdev.cshlp.org/content/24/11/1086.full.html\#ref-list-1

License

Email Alerting Receive free email alerts when new articles cite this article - sign up in the box at the top Service right corner of the article or click here.

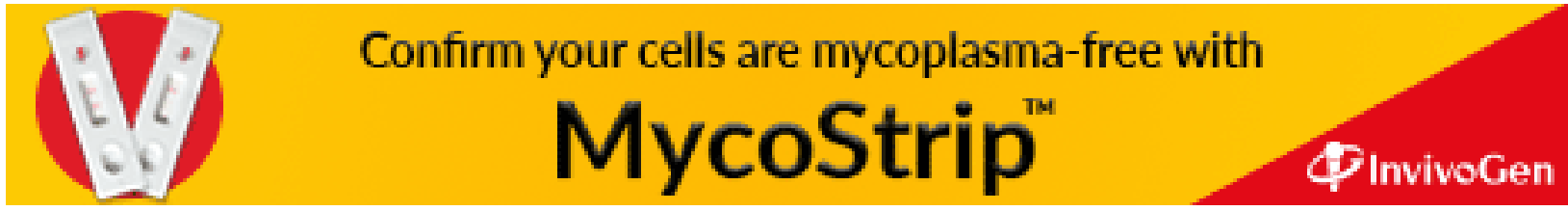

